\title{
ANÁLISE DA RESISTÊNCIA A COMPRESSÃO DE 3 BLOCOS DE FUNDAÇÕES DE UMA TORRE METÁLICA
}

\author{
SOARES TEIXEIRA FILHO, JOSÉ \\ Engenheiro Civil \\ SOARES ENGENHARIA \\ Ceará; Brasil \\ js-engenharia@hotmail.com
}

\author{
FERREIRA SOARES, KARYNE \\ Estudante de Engenharia Civil \\ SOARES ENGENHARIA \\ Ceará; Brasil \\ karynefs@hotmail.com
}

\section{RESUMO}

Em 2019, em Fortaleza, foi executado um serviço de montagem de uma torre metálica autoportante, no entanto, não foi feita por empresa especializada. Com isso, a insegurança em colocar essa torre em funcionamento tomou conta dos responsáveis pela mesma, gerando a necessidade de um estudo para analisar a segurança e a estabilidade. Diante o exposto, este trabalho objetiva analisar a resistência a compressão de 3 (três) blocos de concreto da fundação de uma torre metálica. A partir dos dados coletados e dos resultados dos ensaios de resistência à compressão do concreto, foi possível realizar a análise dos resultados obtidos, tendo como parâmetro a literatura, o projeto disponibilizado e as normas técnicas brasileiras.

Palavras-chave: Blocos de fundações, concreto, torre metálica, estabilidade, segurança.

\section{ABSTRACT}

In 2019, in Fortaleza, an assembly service for a self-supporting metal tower was performed, however, it was not done by a specialized company. As a result, the insecurity in putting this tower into operation took hold of those responsible for it, generating the need for a study to analyze security and stability. Given the above, this work aims to analyze the compressive strength of 3 (three) concrete blocks of the foundation of a metal tower. From the data collected and the results of concrete compression resistance tests, it was possible to perform the analysis of the results obtained, using the literature, the project made available and the Brazilian technical standards as a parameter.

Keywords: Foundation blocks, concrete, metal tower, stability, safety.

\section{INTRODUÇÃO}

Inicialmente, no dia 08/06/2019 (oito de junho de dois mil e dezenove), realizou-se uma vistoria técnica com objetivo de coletar dados do processo de execução de 3 (três) blocos de concreto da fundação de uma torre metálica, como também identificar os materiais utilizados na composição do concreto (traço).

$\mathrm{Na}$ mesma data, realizaram-se três extrações de testemunho, um em cada bloco, com objetivo de determinar a resistência à compressão do concreto da fundação, cujos resultados serão apresentados mais na frente.

A partir dos dados coletados e dos resultados dos ensaios de resistência à compressão do concreto, realizamos a análise dos resultados obtidos, tendo como parâmetro a literatura, o projeto disponibilizado e as normas técnicas brasileiras.

\section{AMOSTRAS}

Para a determinação da resistência à compressão da estrutura de concreto das bases da fundação da torre metálica autoportante, foram realizadas três extrações com diâmetro de $100 \mathrm{~mm}$, uma em cada base, no croqui abaixo estão localizadas as extrações dos testemunhos com a sua respectiva identificação. 


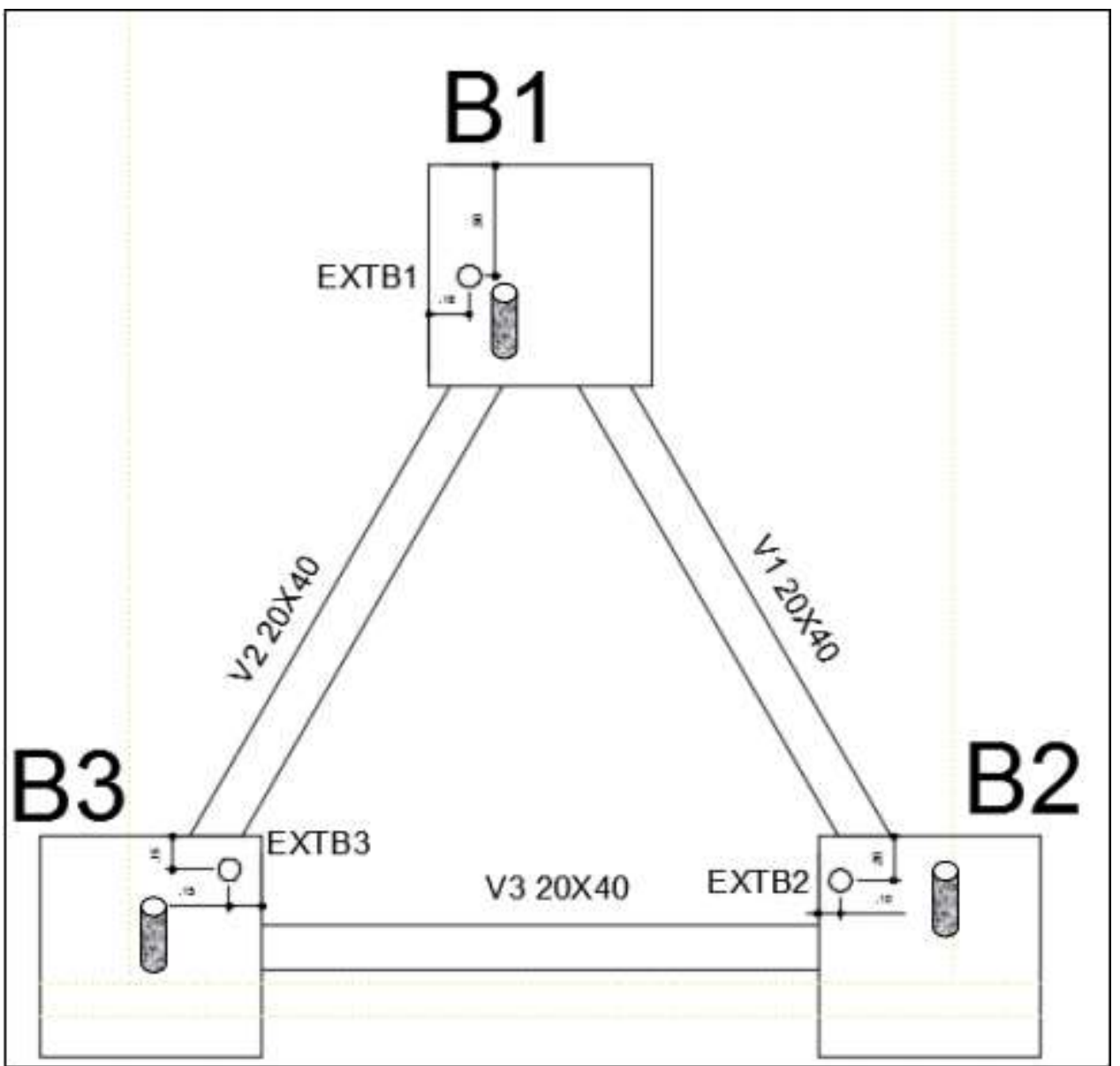

Figura 1: Croqui com as locações das extrações dos testemunhos das bases da torre metálica.

\subsection{Descrição da fundação existente}

O serviço dos três referidos blocos de fundação da torre metálica autoportante foi executado em fevereiro de 2018 pela própria equipe técnica da empresa XX TELECOMUNICAÇÕES, sem a participação de profissionais habilitados na elaboração dos projetos e na execução da fundação.

$\mathrm{Na}$ oportunidade em que estivemos na obra para acompanhar a realização dos ensaios de campo (extração de testemunhos), entrevistamos o Sr. Lula, que nos informou as características geométricas dos elementos estruturais (blocos) das fundações executadas, os materiais utilizados, como também o processo de execução das referidas estruturas da fundação. Dentre as informações, destacamos a utilização do traço de concreto com a seguinte composição apresentada na tabela 1 . 
Tabela 1 - Tabela de composição do traço de concreto

\begin{tabular}{|c|c|c|c|c|}
\hline Traço & $\begin{array}{c}\text { Cimento (SC) } \\
\text { CP II Z } 32\end{array}$ & $\begin{array}{c}\text { Areia Grossa } \\
\text { ( Lata } 18 \mathrm{~L}) \\
M_{\text {unit }} \mathrm{A}=1500 \mathrm{~kg} / \mathrm{m}^{3}\end{array}$ & $\begin{array}{c}\text { Brita } 9,5 \mathrm{~mm} \\
(\text { Lata } 18 \mathrm{~L}) \\
M_{\text {unit }} \mathrm{B}=2000 \mathrm{~kg} / \mathrm{m}^{3}\end{array}$ & $\begin{array}{c}\text { Água } \\
\text { ( Lata } 18 \mathrm{~L})\end{array}$ \\
\hline $\begin{array}{c}\text { Traço } \\
\text { informado }\end{array}$ & 1 saco & 3 latas & 2 latas & 1,4 latas \\
\hline $\begin{array}{c}\text { Traço em } \\
\text { Volume }\left(\mathrm{m}^{3}\right)\end{array}$ & $1 \mathrm{saco}=50 \mathrm{~kg}$ & 0,054 & 0,036 & 0,025 \\
\hline $\begin{array}{c}\text { Traço em } \\
\text { Massa }(\mathrm{Kg})\end{array}$ & 50 & 81 & 72 & 25,2 \\
\hline Traço unitário & 1 & 1,62 & 1,44 & 0,50 \\
\hline
\end{tabular}

Segundo as informações prestadas pelo Sr. Lula, o construtor, foram executados três blocos de concreto armado com dimensões de 1,0 x1,0 m de largura e 2,0 m de profundidade. Os blocos estão unidos por vigas de travamento no topo deles. As dimensões informadas das vigas de travamento são de $30 \mathrm{~cm}$ de largura e $40 \mathrm{~cm}$ de altura. Na figura 2, consta o croqui com as dimensões das estruturas da fundação da torre metálica autoportante.

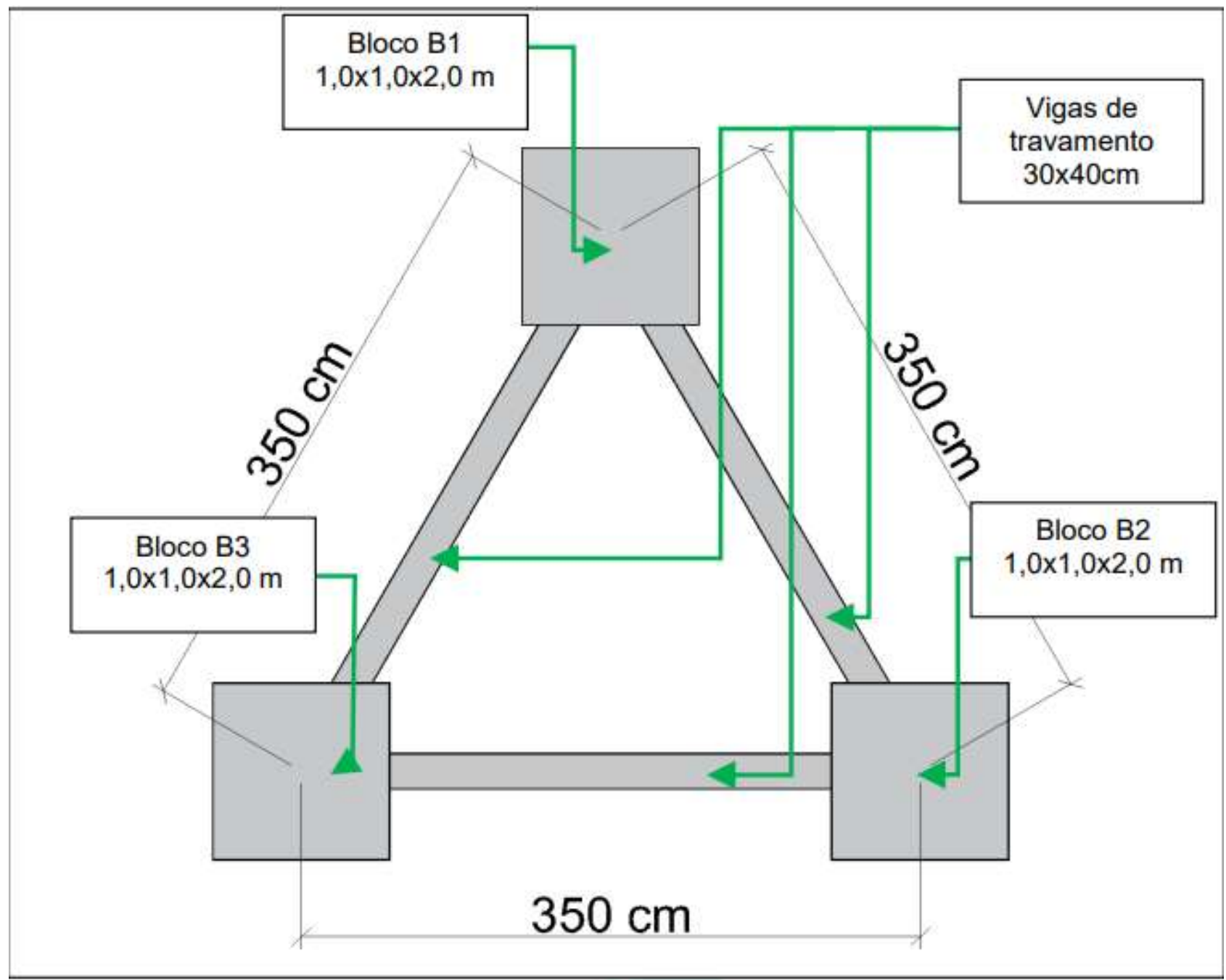

Figura 2: Disposição dos blocos da fundação.

O construtor informou ainda que a bitola da única malha utilizada na armadura de cada bloco é de $10 \mathrm{~mm}$, espaçadas a cada $1 \mathrm{~cm}$. Ademais, mencionou que esta malha foi colocada em cima de uma camada de $5 \mathrm{~cm}$ de concreto magro de regularização. E em cima da referida camada, foi executada uma camada de $140 \mathrm{~cm}$ de concreto ciclópico e sobre esta 
foi executada uma camada de concreto cujo traço consta na Tabela 1. Na figura 3, consta perfil com as camadas de concreto dos blocos da fundação da torre metálica autoportante e a armadura dos blocos.

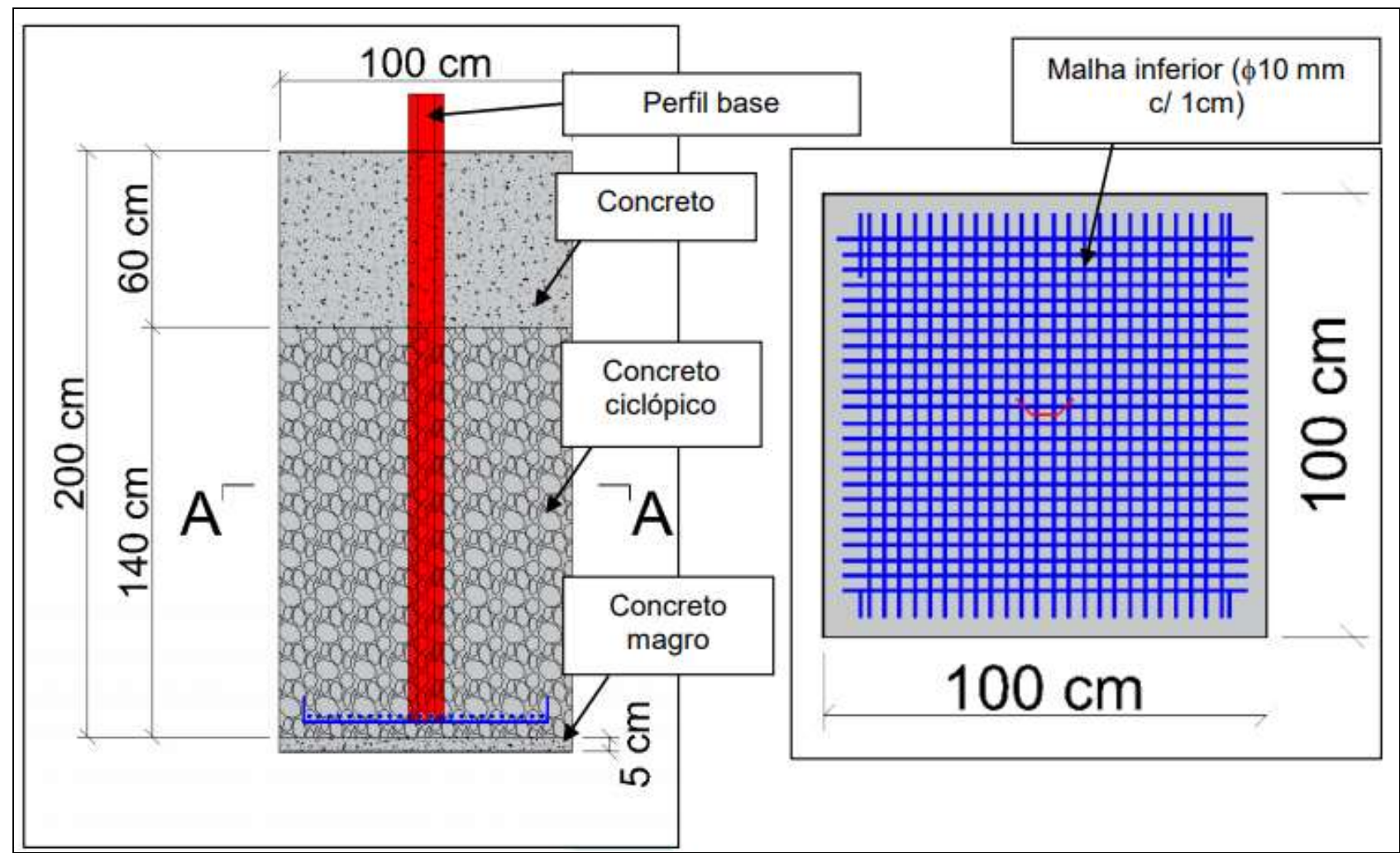

Figura 3: Perfil com as camadas de concreto dos blocos da fundação

Em relação às vigas de travamento, conforme informações do senhor Luís Moreira da Silva, foram adotadas barras longitudinais de $8 \mathrm{~mm}$ e barras transversais de $5 \mathrm{~mm}$ com espaçamento de $15 \mathrm{~cm}$.

Na Figura 4 é possível ver o detalhe da armadura das vigas de travamento.

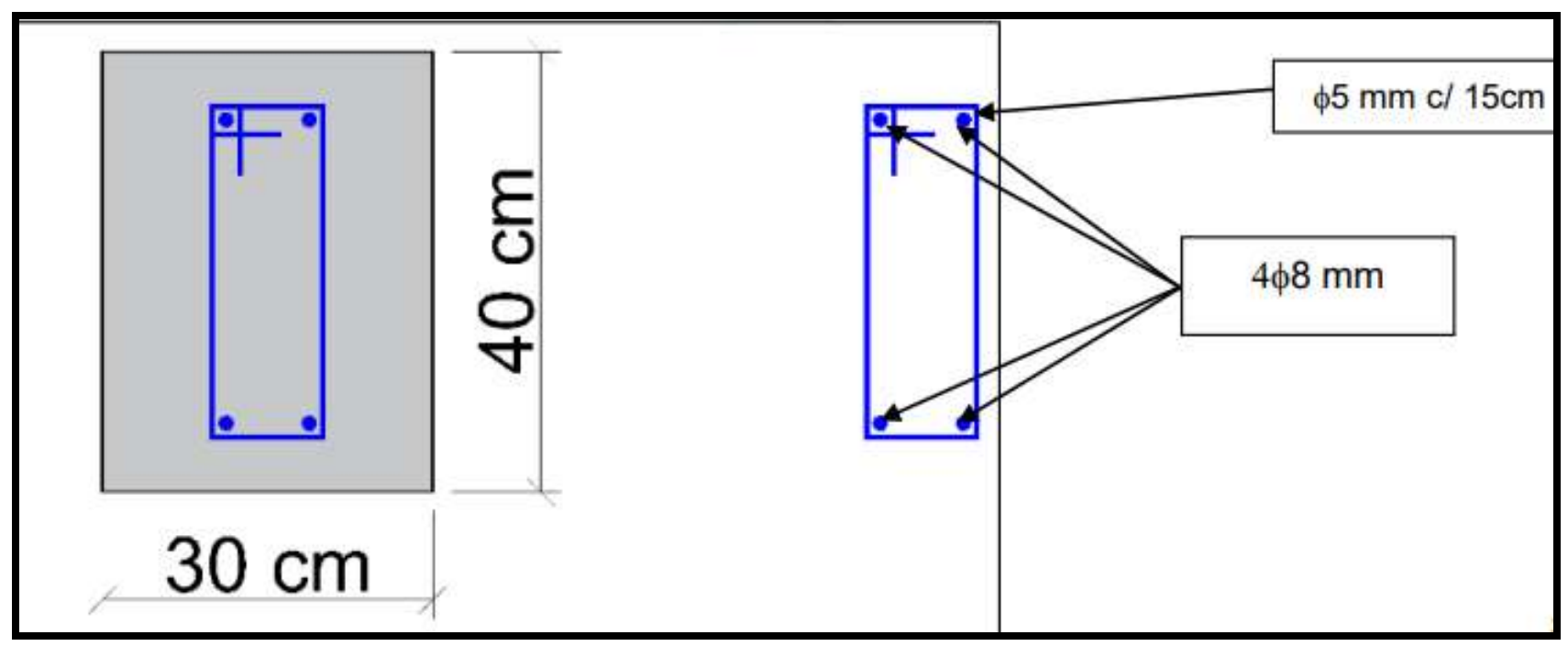

Figura 4: Detalhe da armadura das vigas de travamento

É importante destacar que não foi utilizada betoneira para a mistura do referido traço de concreto e que também não foi utilizado vibrador mecânico para o adensamento do concreto. 


\subsection{Extração e ruptura dos corpos de prova}

A extração dos corpos de prova foi realizada conforme as orientações prescritas na NBR 7680 (ABNT, 2015) Concreto - Extração, preparo, ensaio e análise de testemunhos de estruturas de concreto Parte 1: Resistência à compressão axial.

Para a extração dos corpos de prova, utilizou-se uma perfuratriz DD200 da marca Hilti, com um serra copo diamantado de $100 \mathrm{~mm}$ de diâmetro, fixada em um suporte, verticalmente, para garantir a perpendicularidade do furo com a superfície do elemento estrutural prospectado, ver figura 2.

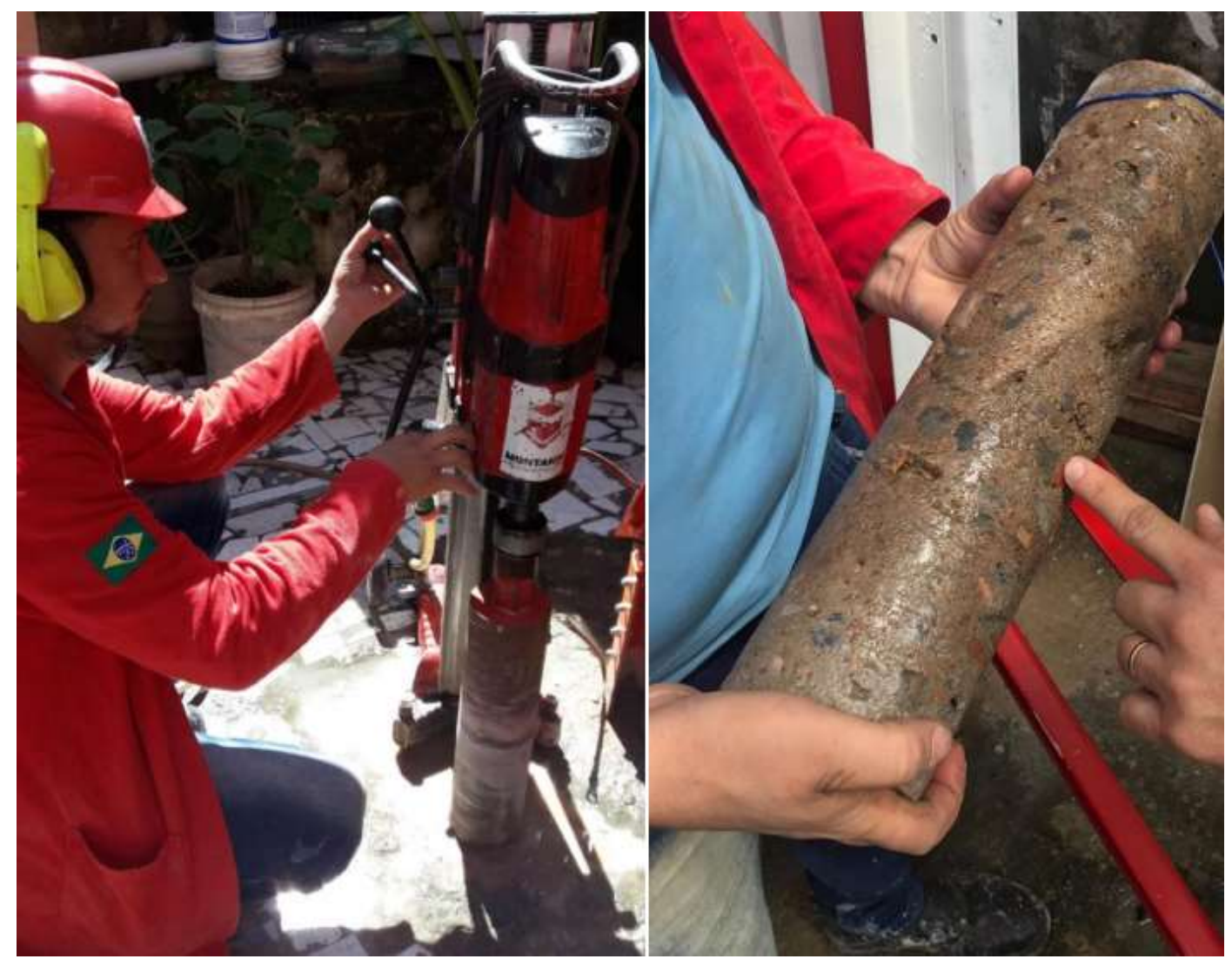

Figura 5: Processo de extração dos testemunhos da base e testemunhos de concreto da base B3.

No laboratório, os testemunhos foram identificados e cortados para retirar irregularidades e, em seguida, o diâmetro e a altura foram medidos com o auxílio de um paquímetro. Depois, os topos dos corpos de prova foram capeados com enxofre, com o objetivo de regularizar a superfície para garantir uma distribuição uniforme de forças nas faces dos corpos de prova na etapa de ruptura, ver figura 3. 


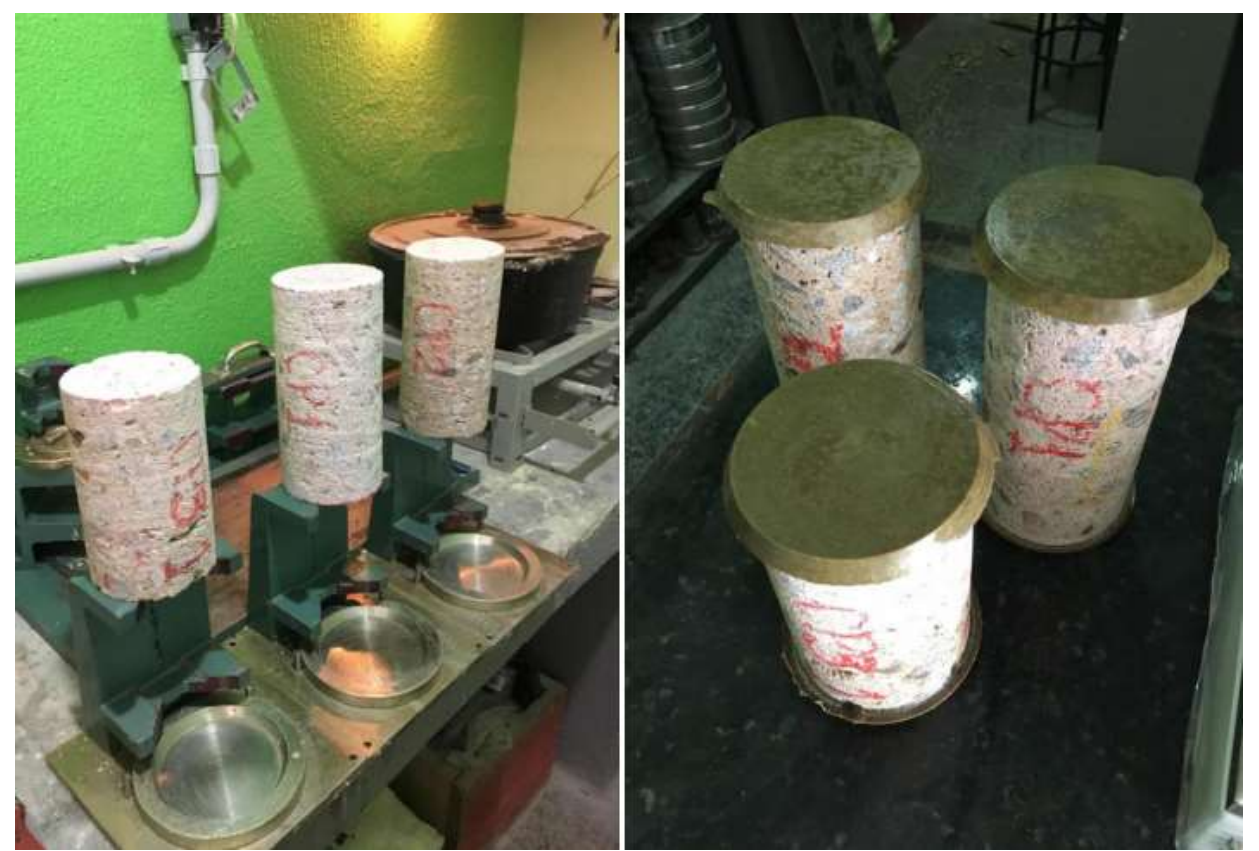

Figura 6: Testemunhos extraídos cortados e com as superficies de topos regularizados com capeamento de enxofre.

Na sequência, as amostras foram rompidas em uma máquina universal de ensaio, da marca EMIC PC100, modelo 100T, calibração $\mathrm{n}^{\circ}$ 1240/18, com velocidade de carregamento de 0,45 MPa/s, conforme a NBR 5739 (ABNT, 2007), ver figura 4.

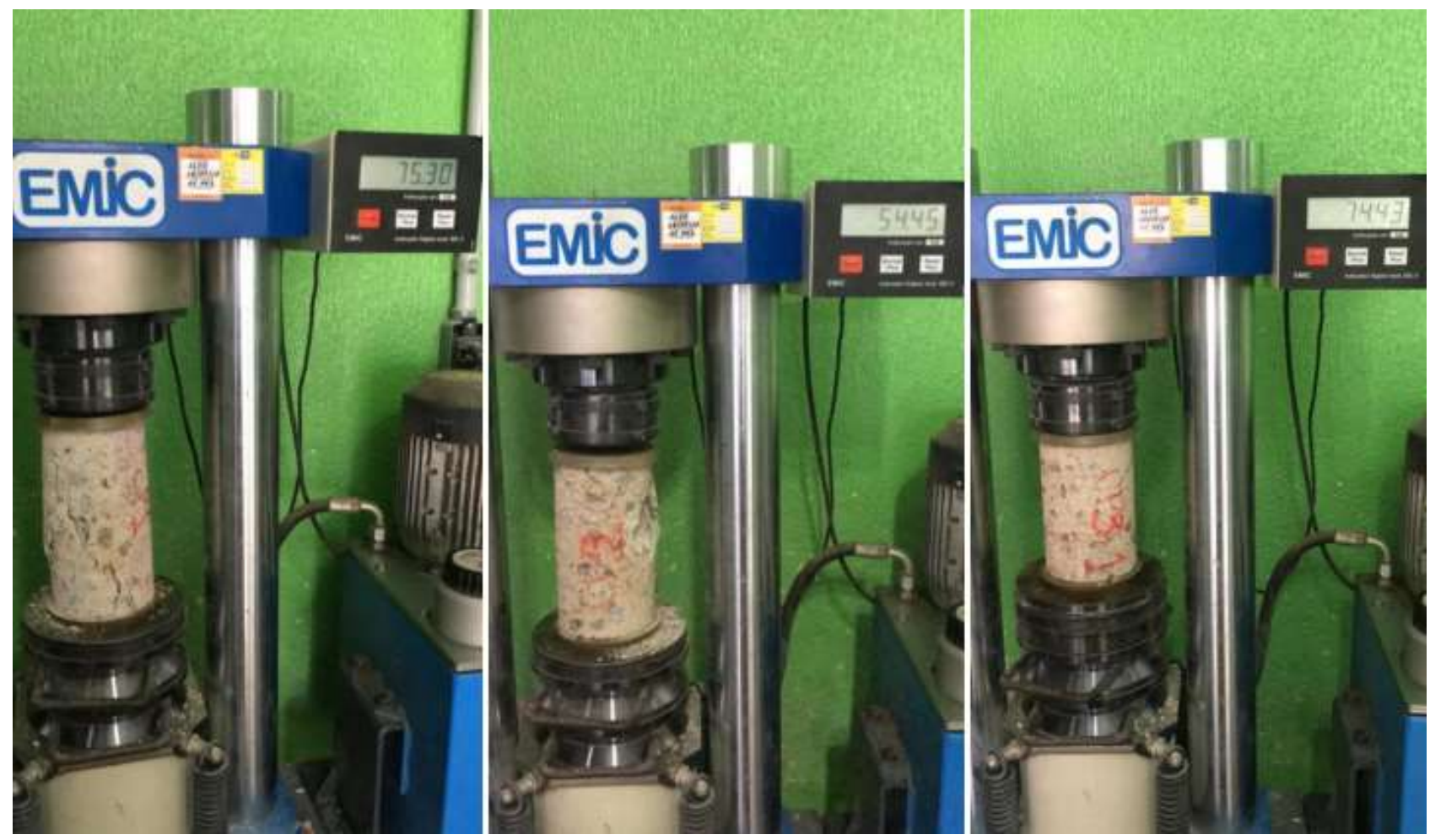

Figura 7: Corpos de prova cortados, capeados e rompidos na máquina universal de ensaio, com o registro das cargas de rupturas.

O valor da resistência à compressão dos corpos de prova, extraídos da estrutura de concreto, expresso em megapascals, foi calculado através da equação 1 . 
Onde:

fc - é a resistência à compressão inicial, em megapascals (MPa);

$\mathrm{Fc}$ - é a carga máxima aplicada, em newtons $(\mathrm{N})$;

As-é a área da seção da amostra, em milímetros quadrados (mm2).

Destaca-se que, após a determinação da resistência inicial, os valores foram corrigidos, através da aplicação dos coeficientes de correção $(\mathrm{k} 1, \mathrm{k} 2, \mathrm{k} 3, \mathrm{~K} 4)$, e expressos em megapascals. Em seguida, calculou-se a resistência à compressão axial do testemunho, através da equação 2, conforme preconiza a NBR 7680 (ABNT, 2015).

$$
\text { fci,ext }=(1+(k 1+k 2+k 3+k 4)) \text { fci,ext,inicial. }
$$

Com isso, constam na Tabela 2, os valores (iniciais e corrigidos) de resistência à compressão dos corpos de prova de concreto, extraídos das bases da fundação da torre metálicas autoportante, conforme preconiza a ABNT NBR 7680$1 / 2015$.

Tabela 2 - Valores de resistência à compressão dos corpos de prova extraídos das bases da fundação da torre metálica.

\begin{tabular}{|c|c|c|c|c|c|c|c|c|c|}
\hline \multirow[b]{2}{*}{$\mathrm{N}^{\circ} \mathrm{CP}$} & \multirow{2}{*}{$\begin{array}{l}\text { Elemento } \\
\text { estrutural }\end{array}$} & \multirow{2}{*}{$\begin{array}{c}\emptyset \text { do CP } \\
(\mathrm{mm})\end{array}$} & \multirow{2}{*}{$\begin{array}{l}\text { Altura } \\
\text { do CP } \\
(\mathrm{mm})\end{array}$} & \multicolumn{4}{|c|}{ Coeficiente de correção } & \multirow{2}{*}{$\begin{array}{c}\mathrm{f}_{\mathrm{ci}, \text { ext, }} \\
\text { inicial } \\
(\mathrm{MPa})\end{array}$} & \multirow{2}{*}{$\begin{array}{r}\mathrm{f}_{\mathrm{ci}, \text { ext, }} \\
\text { corrigido } \\
(\mathrm{MPa})\end{array}$} \\
\hline & & & & K1 & K2 & $\mathrm{K} 3$ & K4 & & \\
\hline EXTB1 & BASE B1 & 100 & 200 & 0,00 & 0,06 & 0,00 & $-0,04$ & 9,5 & 9,7 \\
\hline EXTB2 & BASE B2 & 100 & 200 & 0,00 & 0,06 & 0,00 & $-0,04$ & 6,9 & 7,1 \\
\hline EXTB3 & BASE B3 & 100 & 166 & $-0,03$ & 0,06 & 0,00 & $-0,04$ & 9,5 & 9,4 \\
\hline
\end{tabular}

A partir da média dos três valores individuais dos corpos de prova, apresentados na Tabela 2, extraídos das três bases da fundação da torre metálica autoportante, como também considerando a aplicação dos coeficientes de correção, conforme preconiza a NBR 7680-1 (ABNT, 2015), determinou-se a resistência à compressão real média no valor de 8,7 $\mathrm{MPa}(87 \mathrm{kgf} / \mathrm{cm} 2)$, resistência do concreto das bases pertencente à estrutura de fundação da torre metálica autoportante pertencente a empresa XX TELECOMUNICAÇÕES, localizado no município de Fortaleza, no Estado do Ceará.

\subsection{Característica da torre metálica autoportante}

As características geométricas da torre estão em um projeto que foi elaborado a com a necessidade da avaliação das fundações, já que a torre já estava erguida sem projeto. 


\section{CBPAT 2020 ANAIS

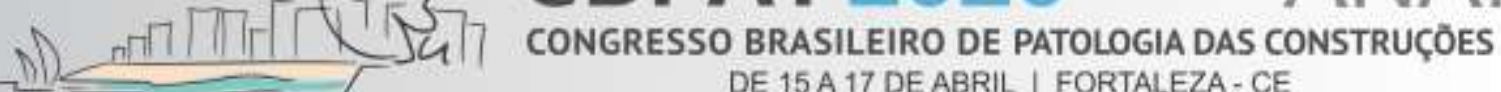 DE 15 A 17 DE ABRIL | FORTALEZA - CE}

Na Figura 8, consta uma imagem destacada do projeto da torre, apresentando a sua topologia.

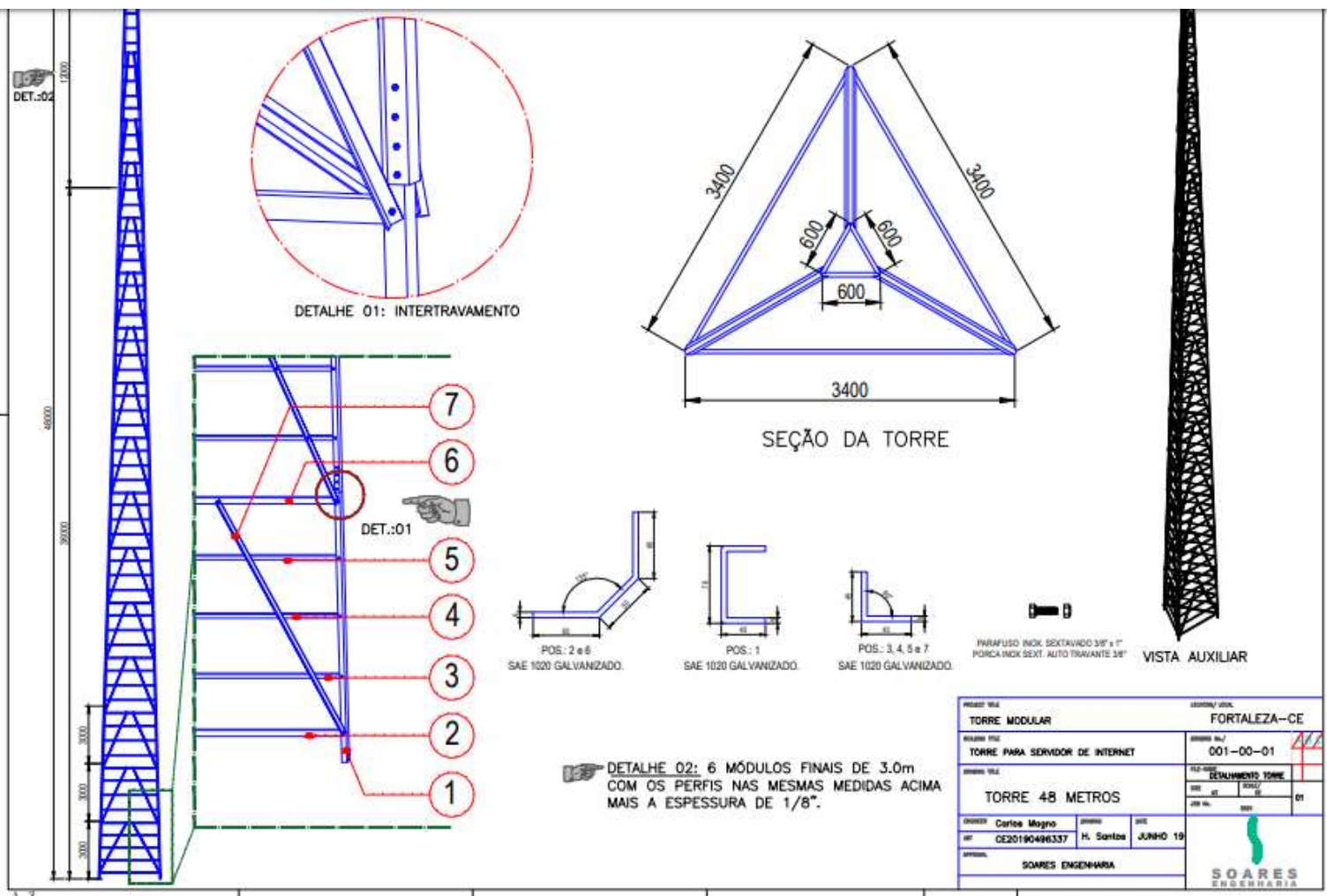

Figura 8: Projeto da torre metálica

A Figura 9 corresponde a imagem da torre em fase de montagem, feitas na data de coleta de dados.
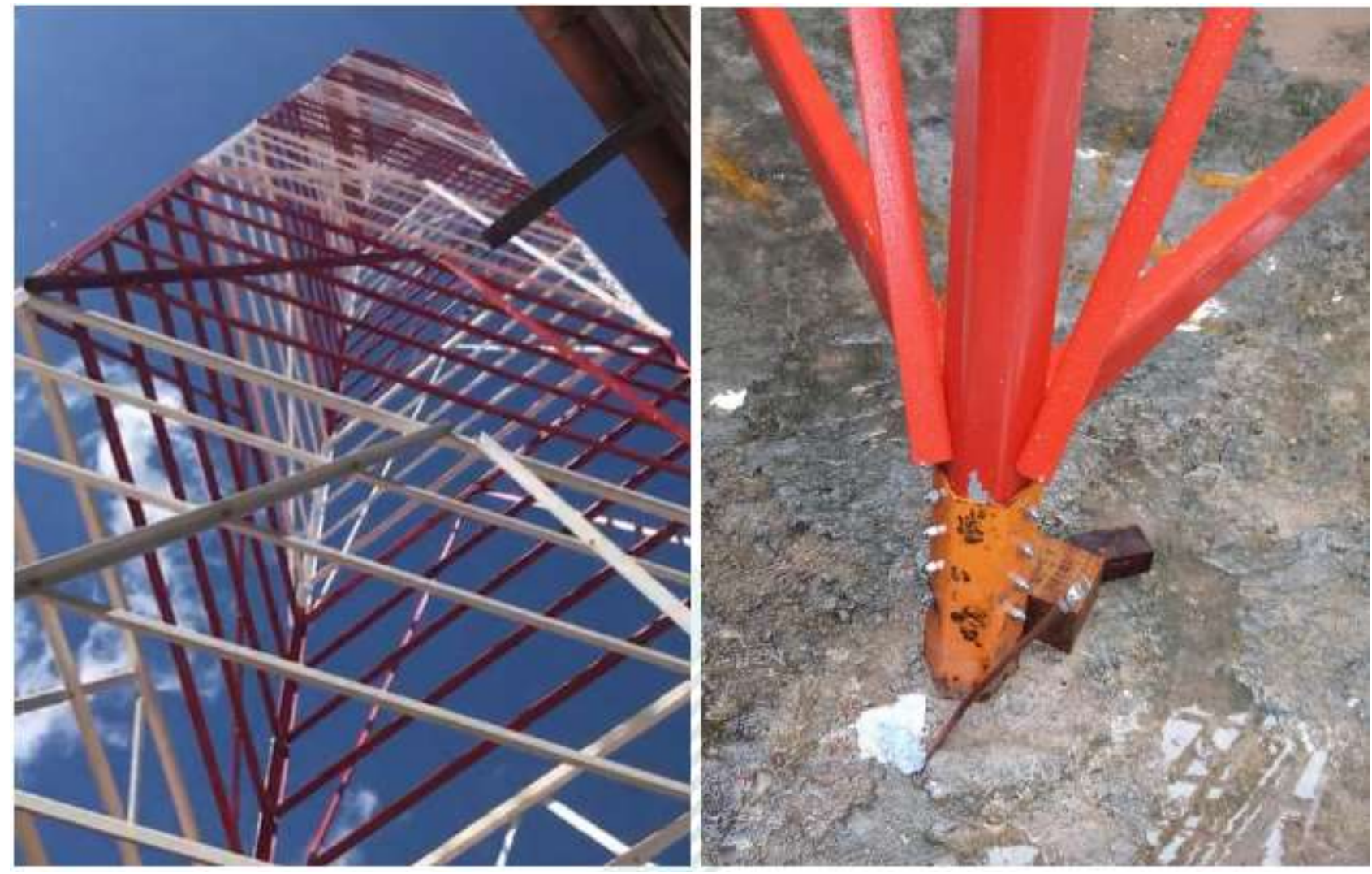

Figura 9: Imagem da torre metálica em construção - superestrutura e detalhe de fixação 


\section{RESULTADOS}

A partir dos ensaios de resistência à compressão dos testemunhos retirados dos 3 blocos, obteu-se os valores de resistência à compressão abaixo:

- Bloco 1 com 9,7 Mpa

- $\quad$ Bloco 2 com 7,1 Mpa

- Bloco 3 com 9,4 Mpa

O concreto executado possui baixa resistência à compressão, resultado da ausência de dosagem de traço inadequado, da deficiência do processo de mistura e da falta de adensamento na fase construtiva das referidas estruturas.

\section{CONCLUSÕES}

Os blocos da fundações de concreto armado da torre metálica autoportante da empresa XX TELECOMUNICAÇÕES, executados no local, não atendem aos critérios mínimos exigidos por normas atinentes.

Destacamos que não foram respeitados os espaçamentos mínimos de armadura dos blocos. Estes deveriam ser de $10 \mathrm{~cm}$ e foram executados (segundo o construtor) com espaçamento de $1 \mathrm{~cm}$. Ademais, a aderência da armadura com o bloco está comprometida devido à utilização de concreto ciclópico nas camadas dos blocos.

A NBR 6122:1996 exige que a resistência característica de elementos de fundação não seja inferior a 15 MPa, para fins de verificação. E o valor da resistência à compressão média, determinada nos ensaios de campo, foi de 8,7 MPa, valor este menor que o mínimo (15 MPa) exigido pela Norma. Os blocos da fundação, portanto, também não atendem a este critério (mínimo) exigido.

Quanto ao perfil geotécnico, destacamos que os blocos das fundações foram executados e assentados sobre a camada de solo argiloso, solo este com baixa tensão admissível (inferior a $1,0 \mathrm{~kg} / \mathrm{cm}^{2}$ ), para o qual se recomenda a execução de fundações indiretas.

Outra importante constatação é que de acordo com a Telebrás (SDT-240-410- 600, 1997), a superfície do concreto da fundação da estrutura deve ficar arrasada no mínimo $20 \mathrm{~cm}$ acima do terreno, devendo ser inclinada e desempenada a fim de evitar o acúmulo de sujeira e água na base da torre. Esta condição não foi verifica in loco. A fundação foi executada abaixo do nível do terreno.

Diante o exposto, recomendamos a desmontagem da torre metálica, a demolição dos blocos da fundação da torre metálica autoportante, a realização de uma sondagem à percussão do tipo SPT, a contratação de profissional habilitado para fins de elaboração de projeto estrutural da fundação e execução da estrutura e a realização de controle tecnológico no que se refere ao concreto a ser utilizado na estrutura.

\section{AGRADECIMENTOS}

Agradecemos a empresa SOARES ENGENHARIA, pelo o apoio e oportunidade em permititir a realização deste trabalho.

\section{REFERÊNCIAS}

Nota Fiscal nº 000023678, de 17/02/2018, da empresa ESTRUTURAL.

ABNT. NBR 6118 - Projeto de estruturas de concreto - Procedimento. Rio de Janeiro, 2014.

ABNT. NBR 6120 - Cargas para o cálculo de estruturas de edificações. Rio de Janeiro, 1980.

ABNT. NBR 6122 - Projeto e execução de fundações. Rio de Janeiro, 1996. 


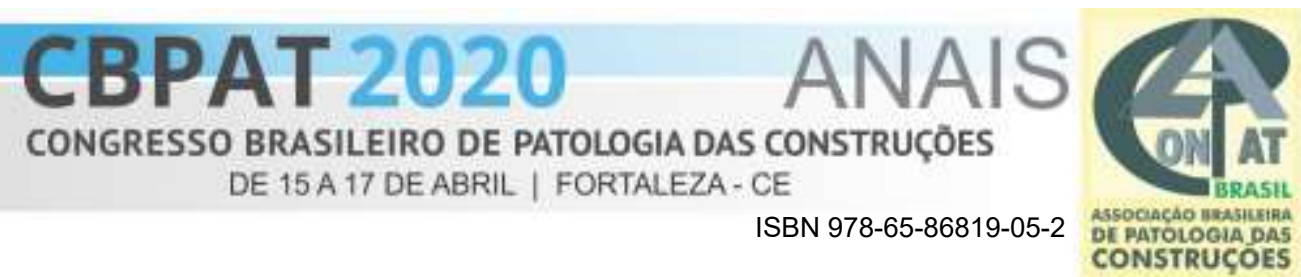

ABNT. NBR 6123 - Forças devidas ao vento em edificações. Rio de Janeiro, 1988.

TELEBRÁS. SDT-240-410-600 - Procedimentos de projetos para torres metálicas auto-suportadas, estaiadas e postes metálicos, 1997.

TELEBRÁS. SDT-240-400-702 - Especificações gerais para adoção de parâmetros básicos e apresentação de memorial de cálculo para torres e postes metálicos, 1997.

VAZ, L. E. Método dos elementos finitos em análise de estruturas. 1ª ed. Rio de Janeiro: Elsevier Editora Ltda, 2011. 